\title{
A BANALIDADE DO VIVER NA CONTEMPORANEIDADE: sobre depressão, luto e
} felicidade

\author{
Carlos Vitor Esmeraldo Albuquerque Beserra ${ }^{1}$; Khalina Assunção Bezerra ${ }^{2}$
}

\section{Resumo:}

O presente artigo teve como objetivo analisar literária e, portanto, teoricamente alguns aspectos da subjetividade da época contemporânea, procurando demonstrar como o modelo atual de estilo de vida indaga sobre uma maneira de viver em constante subversão de valores e sentimentos, resultando no conglomerado de resistências a vivenciar um luto, seja qual for sua espécie, e potencializando, assim, emersões de psicopatologias, no caso do presente estudo, a depressão. Para tanto, intitulou-se como banal os tempos modernos, sugerindo um prognóstico fatalista, mas repleto de motivações para tal. Como complemento da análise, buscou-se averiguar o argumento sobre a felicidade, diretamente ligada ao tema, e como ela tem sido responsável por vários fenômenos presentes no estudo em meio às reflexões sociais, segundo algumas óticas dos teóricos e em seu conceito de senso comum. São analisadas, também, características do processo de luto, destacando a interrupção da experiência do pesar como prejudicial e distanciadora do conhecimento sobre a finitude, entendendo que a inexperiência desse processo advém de uma conjuntura social que impede os movimentos de infelicidade e demonstração dessa. Assim, a análise demonstrou um aparato atual dos modos de viver, oportunizando alguns fenômenos em suas caracterizações na modernidade.

Palavras chave: Depressão, luto, felicidade.

\begin{abstract}
:
The present article had the intention to analyze literarily and, therefore, theoretically some aspects of the subjectivity of our time, trying to demonstrate how the current model of lifestyle, asks us about a way of life in constant subversion of values and feelings, resulting in the conglomerate of resistances, to experience a mourning whatever it is, its species and thus potentializing, emergencies of psychopathologies, in the case of the present study, depression. For this, modern times was called banal, suggesting a fatalistic prognosis, but filled with motivations for such. As complement to the analysis, it was sought to find out the argument about happiness, directly linked to the theme and how it has been responsible for many phenomena present in the study, amid the social reflections, according to some optics of the theorists and in its concept of common sense phenomena. Are also analyzed, characteristics of the process of mourning, highlighting the interruption of the experience of regret, as detrimental

\footnotetext{
${ }^{1}$ Graduando em psicologia pela Faculdade Maurício de Nassau. E-mail: carlosvitoranimes@ hotmail.com

${ }^{2}$ Graduada em psicologia pela Universidade Federal do Piauí. Especialista em saúde mental pela Faculdade Latino-americana de Educação. Mestre em psicologia pela Universidade Federal do Ceará. Integrante do Núcleo de Psicologia do Trabalho - NUTRA/UFC. Professora na Faculdade Maurício de Nassau. Professora substituta do curso de psicologia da Universidade Federal do Piauí. Coordenadora de saúde mental e da educação permanente em saúde na Secretaria Municipal de Saúde de Parnaíba. E-mail: khalinabezerra@ hotmail.com
} 
and distant from knowledge about finitude, understanding that the non-participation of this process, comes from a social conjecture that negativizes the movements of unhappiness and demonstration of this. Like this, the analysis seeks to demonstrate a current apparatus of ways of living, providing some phenomena in their characterizations in modernity.

Key Words: Depression, mourning, happiness. 


\section{Introdução}

$\mathrm{Na}$ contemporaneidade, falar abertamente sobre o próprio sofrimento é raro. Mais incomum ainda é ser escutado diante de um pedido de ajuda. Tais exemplos nos fazem lembrar que são tempos difíceis para se comunicar intersubjetivamente, e, consequentemente, mais fácil para o surgimento de somatizações, que seriam sintomas físicos derivados de causas emocionais que não conseguem ser identificados e sanados com remédios, mas somente com a identificação e expressão dessas emoções obstruídas.

Muitas vezes esses sentimentos estancados, resultam em uma infelicidade potencializada, que para os indivíduos inseridos nessa circunstância, encontram-se em um estado denominado de depressão (LEADER, 2011). A doença do século, como é categorizada, vem destruindo e dificultando a existência de diferentes pessoas em vários locais do mundo (VIEIRA, 2016). Em razão de não saber como lidar com a propagação da cultura da ganância, da violência, da falta de expressão diante da dor, e vivendo na ditadura da felicidade, o sujeito que se apresenta triste no local onde a ideia absoluta é a de vida feliz, e o infortúnio não é bemvindo, logo é lançado à margem do social, pois sua improdutividade não é bem quista no modelo de sociedade padronizado pela felicidade.

Ao passo que essa temática é discutida recorrentemente em diversos meios, da academia ao senso-comum, a percepção que fica é de que há uma validade e relevância para essa comunicação trazida, buscando provocar um diálogo para que possíveis discussões surjam como norteadoras. Camus (2013, p. 21) aborda a importância de tal discussão.

\footnotetext{
Continuamos fazendo os gestos que a existência impõe por muitos motivos, o primeiro dos quais é o costume. Morrer por vontade própria supõe que se reconheceu, mesmo instintivamente, o caráter ridículo desde costume, a ausência de qualquer motivo profundo para viver, o caráter insensato da agitação cotidiana e a inutilidade do sofrimento.
}

Ao tratarem sobre essas ideias, algumas perspectivas têm posicionamentos em autores filósofos (Hadot, Giannetti), psicanalistas (Leader, Kehl, Freud), psicólogos e psiquiatras (Parkes, Vieira, D’assumpção), que guiarão esse trabalho, apresentando os diversos posicionamentos que possam vir a orientar meios de se retirar progressivamente o estigma oneroso que o tema possui, pois a melancolia não é mais tratada como criação e estigma artístico, e sim em linhas atuais, como uma psicopatologia, uma negação caracterizada por quem, muitas vezes, prefere não enveredar na correnteza social do ter e do aparentar diante desse ter alegria. A depressão é, quando exposta dessa forma, um ponto de felicidade alienada, 
sensação causada pela incapacidade de não sentir felicidade, mas dissimular o sentimento em decorrência de uma aceitação de grupos sociais, que analisam e aplaudem quem finge regozijar esse momento configurador de uma sociedade emersa em vivências mascaradas (KHEL, 2009).

No que concerne à caracterização da pesquisa, essa se trata de um estudo descritivo, qualitativo, que procurou assimilar o conteúdo exposto pela ótica da Tanatologia, viés abrangente, aqui servindo como analista da subjetividade dos tempos pós-modernos. Houve a busca na literatura, com base nos questionamentos trazidos, da reflexão de alguns motivos que denotam as dificuldades desse tempo para ser feliz e não um conceito da psicopatologia.

A divisão do artigo em tópicos com o desdobramento de assuntos específicos traz no decorrer da pesquisa a característica de condensação dos fatos, demonstrando que uma amostra teórica e conceitual tem ligação com a outra que a sucedeu para juntas discernir com maior facilidade e compreensão o proposto pelo trabalho, não findando em conclusões, e sim em questionamentos. A primeira parte apresenta algumas contextualizações sobre a contemporânea vida ocidental, logo em seguida, é apresentada uma equiparação e argumentação sobre a relação de depressão e luto, ressaltando quando este não é elaborado e não tem iniciado o seu processo. Logo em seguida, é produzida uma discussão sobre a exigência permanente do conceito de felicidade a toda uma sociedade em sua tradição, refutando que felicidade é essa e questionando se ela realmente existe entre os sujeitos da modernidade.

\section{Metodologia}

Para a elaboração da presente pesquisa foram selecionados livros impressos e que articulam com a temática abordada. As obras selecionadas datam o período entre 2009 a 2016 e têm ganhado notoriedade ao longo do tempo. Tanto a Tanatologia, como a Filosofia e Psicanálise, foram fontes de pesquisa para afunilar o tema tratado, intentando dar concisão ao olhar de análise e também provocando questionamentos. Sobre o extraído em cada livro, há a percepção de ampla conexão com os temas apresentados, um preenchendo o outro de sentido, dando formato de problemática selecionada e sedimentada para o estudo escolhido.

Já para a construção foi realizado metodologicamente um estudo de cunho bibliográfico, que para Gil (2008) é um estudo composto por publicações que embasaram a reflexão que se segue. É válido salientar a utilização da técnica de leitura de formação subjetiva, que considera a dialógica entre autor e leitor, trocando sentido e compartilhando um entendimento mútuo de leituras, como pontua Larrosa (2003). 
Entrementes, as obras de cada autor utilizadas foram escolhidas pela familiaridade com o tema abordado, como o livro O tempo e o cão (2009), de Maria Rita Khel - inclusive tendo ganhado o prêmio Jabuti na área de Psicologia com essa obra. O mesmo acontece com Parkes e sua obra reconhecida mundialmente, Luto (1998). É válido ressaltar a incidência de Leader, psicanalista americano essencial nessa pesquisa através de sua obra intitulada Além da Depressão (2011). É frisado também que a utilização como embasamento de alguns artigos, que discorrem sobre o tema da subjetividade e análise contemporânea, permitiu adentrar na interpretação de alguns comentadores. Desse modo, reafirma-se que a investigação foi estritamente bibliográfica, além de qualitativa, descritiva e ao máximo integrada, por colocar em um envoltório os tratados afins de cada fenômeno (GIL, 2008).

Enfim, por se tratar de pesquisa não quantitativa, a produção busca alcançar o saber teórico sobre o ramo escolhido para investigação, não desvalorizando o saber interpretativo e empírico, mas visando coadunar inicialmente na interpretação do trabalho o foco na pesquisa literária, e a posteriori, com mais profundidade na pesquisa material e, concretamente, o sensibilizado aqui. Conclui Silva (2010, p. 6), explicitando acerca da pesquisa qualitativa na Psicologia e sua relevância:

A abordagem qualitativa trabalha com valores, crenças, representações, hábitos, atitudes e opiniões. Ela aprofunda a complexidade dos fenômenos, fatos e processos; passa pelo observável e vai além dele ao estabelecer inferências e atribuir significados ao comportamento.

Nessa perspectiva, a abordagem utilizada tem esteio em um comprometimento de auxílio à reflexão e no intento de oferecer informações aos leitores acerca dos estudos e resultados vigentes na interpretação de atuações apresentadas pelos sujeitos inseridos na sociedade atual.

\section{Tempos banais: só mais um na multidão}

Na história, a felicidade sempre foi uma temática de interesse para pesquisas entre os pensadores desde a Grécia antiga às décadas moderna e pós-moderna e entre os grandes intelectuais de diversas áreas do saber. Aristóteles pregava uma virtude da personalidade, habitual e natural do ser; Sócrates a atribuía ao espaço de reflexão moral que capacitava o homem de ser feliz ao expandir sua hombridade; já Platão a postergava para o além-vida, aproximando-a a um conceito atualmente religioso e ascético (MARCONDES, 2007). Cada qual pôde contribuir com essa construção conceitual, a partir de sua visão de determinada 
situação cronológica e normas sociais, sua vida e momento histórico. Em pleno século XXI não é diferente, balizado pela conjuntura da sociedade somada a sua história, que remete o homem ao seu desenvolvimento dentro de sua cultura e história de sua época, é apresentado o momento em que se vive a sintomatologia do desprezo pela vida. Como noção geral de felicidade, existe um conjunto de crenças e culturas vivenciadas no meio chamado sociedade, no qual fazem surgir os lutos que não puderam ser falados, não puderam ser vivenciados e expressados, pois a fixidez funcional de agir pela vontade dos outros ilustra que viver triste e, por muito tempo assim, é falta de respeito com o resto de seus semelhantes, que não suportariam ouvir suas lamúrias e suas derrotas, aniquilando o modelo de perfeição de quem ouve.

Nesse pensamento, contribui Barros Filho e Karnal (2016, p. 17)

E também a ideia de atrelar a felicidade a coisas denuncia uma impossibilidade de satisfação, porque basta ir à rua para percebermos que não temos muito mais do que temos. E sempre será assim. A grande promessa da nossa sociedade é que sempre haverá aquilo que não temos e, portanto, desejamos.

A partir desses apontamentos, surge a indagação sobre ser feliz e como a superficialidade dada ao tema tornou-se caro à discussão, visto que inúmeras são as fontes que se aproveitam da situação atual para render benefício próprio. Hoje, já é evidente o caráter penoso e biológico da depressão, há alterações que agravam a situação tanto no cérebro como pelo resto do corpo, tornando de praxe uma pessoa com depressão ter seu estado de humor abalado e desanimado, dentre muitos outros fatores que se encaixam para propor um diagnóstico dessa doença, hoje problema prioritário de saúde pública (DALGALARRONDO, 2008). No compêndio de psiquiatria, Sadock e Sadock (2007) averiguam a depressão como um estágio do luto, fazendo parte de seu processo e a anunciam como um transtorno de humor que faz parte de nossa história desde a Antiguidade, tanto nos textos bíblicos como nos determinantes de nossa história. Os mesmos autores demonstram sua presença no Manual de Diagnóstico e Transtornos Mentais (1999), suas incidências e escalas de volubilidade mensuradas ao longo dos anos (SADOCK; SADOCK, 2007).

Dessa maneira, a depressão-doença, como nomeada por alguns psiquiatras, tem escopo no biológico defronte a disfuncionalidade neuronal e de seus sistemas enredados pelos hormônios do prazer e de um humor radiante, degradando a ação salutar do indivíduo em seus usufrutos diários (VIEIRA, 2016). Mas a referida variável desse processo humano não é o objetivo da pesquisa em questão, dado que não há competência para tal, e os tributos aqui se referem à Psicologia e seus estudos, afastando-se não em distância, mas em análise das 
disciplinas de abordagem biológica. É imprescindível pontuar que não há descuido de tal elemento em nosso estudo, mas uma preferência por outra dimensão de acinte teórico.

Nesse sentido, ainda é válido destacar a discussão relativa à medicação apontando que mesmo com sua relevância a mesma não possui total abrangência na recuperação desse ser em padecimento. Assim, aponta-se aqui um aporte ao tipo de conduta de atenção à saúde que apenas vidra-se na possibilidade da farmacologia como fiel aliada, negligenciando a importância da subjetividade da escuta com afinco e afeto, não perpassando um respeito pela alteridade existencial daquele indivíduo que ali carece de ajuda (LEADER, 2011). Leader (2011, p. 25).) reforça esse posicionamento ao afirmar que "quanto mais a sociedade reforçar os valores de eficiência e de produtividade econômica, mas a depressão proliferará como uma consequência necessária".

Conquanto, incitar o verdadeiro teor medicinal de tais pílulas e sua eficácia sem o crivo psicológico e humano não é esvaziar a dor do outro que sofre de infelicidade, mas topar e impossibilitar uma reação existencial. Giannetti (2002, p. 176) chama a atenção para o consumo da felicidade plástica através do restrito uso de medicação.

A mesma civilização tecnológica e de alta pressão competitiva que, por um lado, destrói as bases da felicidade instintiva no animal humano, vem por outro, acenar com a promessa de um paraíso sobre a terra por meio do consumo desenfreado e de um simulacro de felicidade quimicamente determinada.

Diante desse fato, o entendimento reflexivo sobre a vida e suas demandas emotivas tem como horizonte a morte em sua ideal posição de afirmação do ser e sua iminência como legitimação da óbvia impermanência corpórea/consciente na terra. Para tanto, o espanto referente ao luto nesse processo é perceber que demais acontecimentos relacionados à morte afrontam e entristecem. Mas enquanto os indivíduos resistirem a querer falar sobre isso e vivenciar as pequenas mortes diárias, o teor prejudicial será espalhado na cultura consciente dos seres de relação. Hadot (2016, p.135) aponta uma elucidativa visão sobre a questão:

(...) é preciso realizar cada ação como se fosse a última; ou ainda: é preciso viver cada dia como se fosse o último. Trata-se de se conscientizar de que o momento que ainda está sendo vivido tem um valor infinito.

A morte, teoricamente, é vista como duas dimensões que cercam a finitude, sendo elas: a morte simbólica e a morte concreta. Esses dois conceitos são entendidos como uma forma solene de desenvolvimento do homem, pois o ato de viver já pressupõe o perder, dado que, do início ao fim, biologicamente perdemos, mas biologicamente necessitamos dessas perdas para o corpo madurar, ressoando esse conceito para os relacionamentos que se vão, para as fases da 
vida, para os momentos profissionais, isto é, em todos os âmbitos a morte simbólica tem presença. Já no referente à morte real, seria a perda da atividade vital, na qual o corpo e sua consciência se vão, a mente é desativada, o corpo vai esvaindo e nutrindo seres terrestres e equilibrando a própria terra (KOVACS, 1992).

\section{Depressões e luto: uma questão de afinidade}

A singularidade de cada sujeito se expande em diversos esquemas de conexão, desde sua vida intramundana (vida de avaliação de si em profundidade) à vida de suas relações íntimas e superficiais e como ele se porta diante de suas questões espirituais e objetais. No entanto, é vital salientar que tudo está em constante mudança, e, portanto, transformação, propondo diante de tal afirmativa a percepção de situações inevitáveis como a passagem pelas pequenas perdas e separações que a existência incita. A afinidade que liga os temas em questão, tanto depressão como luto, é identificada quando o fenômeno luto é recebido pela sociedade como um sinal catalisador da depressão, ou seja, quando impossibilita o sujeito de fazer as tarefas que este exercia anteriormente ao processo de luto dificultoso, apresentando a condição de enlutado como um enquadramento psicopatológico.

Aqui o fenômeno luto é entendido como um conjunto de fatores que validam a experiência da perda, podendo transitar por fases que vão desde a negação à aceitação, ser dividido genericamente em concreto e simbólico, em que este é mais comum nas ditas depressões pelo fato de surgirem quando não se consegue lidar com as perdas cotidianas, variadas e angustiantes. Em consequência disso, não há a exposição e nem a procura de conscientizar uma comunicação para consigo que seja eficaz, em ressignificar a dor enfrentada no dia a dia (KÜBLER-ROSS, 2008).

Já o luto concreto parte sempre de uma perda real e factível corroborando com a ideia inconsciente, porém, verdadeira de morte. Perde-se um ente querido e não tão querido assim; perde-se pessoas com as quais temos afeto, mas nunca chegamos a ver; perde-se diante de catástrofes pessoas que sentimos e garantimos automaticamente um estado tristonho pelo percebimento de tais fatos, são esses lutos incomuns, mas diários, que se não trabalhados, conversados e transvalorados tendem a causar comumente conversões depressivas por ativarem e despertarem em nós o não vivenciado no passado. Assim,

A dor do luto é tanto parte da vida quanto a alegria de viver; é, talvez, o preço que pagamos pelo amor, o preço do compromisso. Ignorar este fato ou fingir que não é 
bem assim é cegar-se emocionalmente, de maneira a ficar despreparado para as perdas que irão inevitavelmente ocorrer em nossa vida (...) (PARKES, 1998, p. 22-23).

No desenrolar dessas problematizações, abordar-se-á a subjetividade do tempo em que vivemos, ou seja, a particularidade de nossa contemporaneidade. Nesse contexto, impressiona saber que referências de atividades humanas como a tecnologia e a globalização foram criadas com o intuito de ajudar e promover o desenvolvimento humano em suas atividades, porém se tornaram fontes de descaracterização do humano enquanto personalidade (ROSA; SANTOS, 2015). Exemplo factível seriam as redes sociais, que servem para estreitar laços com pessoas desconhecidas passando a vigorar um relacionamento de amizade e aceitação.

Constantemente nos deparamos com pessoas que vivem cercadas de felicidades via rede social, mas que, na realidade, encarapuçam-se na dissimulação oferecida por essa ferramenta, enquanto sua subjetividade é manufaturada a uma busca de perfeição que não é substancial de nenhum humano alcançar (ROSA; SANTOS, 2015). Destarte, causa estranhamento analisar o século XXI e perceber que o que veio para acrescentar ao homem desnaturaliza e adoece quem se deixa absorver por tal fonte.

Nesse quesito, o tanatólogo D’Assumpção (2011, p. 67) diz que

O ser humano do século XXI é essencialmente uma pessoa angustiada. O que diz ser progresso em nossa sociedade é, na realidade, um terrível manancial de angústias que nos atormentam diariamente.

Esse indivíduo hodierno é composto por vontades genuínas, porém, quebradas e abaladas pelo conjunto de fatores que denominam a cultura ocidental. Ao passo que ele quer ser feliz à sua maneira é marginalizado por expor-se diferentemente, chamando a atenção da comunidade, que nesse caso é a responsável direta por aperfeiçoar a moral local e os bons costumes, e o jeito de ser de cada um que equivale nesse ínterim para todos. Atinente à causa, Kehl (2009, p. 140) declara que: "O depressivo é aquele que tenta se colocar sempre fora do tempo dos outros, ou do tempo imposto pelo Outro", como uma consequência desse pulo, para fora da forma impetrada.

Há, teoricamente, uma relação entre o processo de luto e a depressão: tanto o luto como a melancolia têm em si uma questão de afinidade complexa, quase perplexa e quando se esclarece a ligação entre ambas inicia-se um mergulho no que há por trás do fazer viver em meio a um mundo analiticamente deturpado de valores. Tal fato gera o símbolo de decaimento do próprio ser humano, que desprovido de conhecimento de sua raça e de suas dores faz surgir comportamentos históricos, mas com a roupagem de sua época. Um deles é a automutilação, 
fator que na clínica vem ocorrendo de maneira considerável em número de casos e incidências em jovens adolescentes causada muito superficialmente em explicação teórica por uma crise de existência, na qual a carne cortada torna-se um alívio para a dor maior cristalizada na existência e na circunstância emocional, objetificada em um isolamento e não mais protagonismo (VILHENA; PRADO, 2015).

Decerto, quem passa por tal situação necessita de muito mais auxílio e acolhimento do que o cogitado ultimamente em nossas faculdades e literaturas. Nesse sentido, tal acontecimento não é um acidente de percurso do século, e sim um fenômeno passível de alarde para o novo conteúdo psicológico de estudos e buscas de resoluções (VILHENA; PRADO, 2015).

Nessa era o que claramente se percebe é o surgimento de vários episódios idiossincráticos a condição de vida, em que há uma forte agressividade à vida mental. Seria confortável colocar sem explanações, a culpa ou decorrência desses fatores ao fato de cada vez menos as pessoas pararem para refletir e perceberem que as perdas são suscetíveis aos ciclos da vida, e que de forma natural, tais perdas são belas e necessárias ao contexto de entendimento de mundo ao invés de dolorosas. Por essa via, parece se identificar que o luto, a melancolia, a depressão, as situações de automutilação e as perdas de sentido na vida, todas abrangentes, podem fazer parte de uma linha de intersecção onde o eixo de convergência seria justamente a morte e suas ausências de aproximação e manuseio compreensivo, destacando assim, a finitude e impermanência como aliadas a um pensamento faltante, o de vivenciar nas dificuldades naturais da vida a expressão da dor.

Desde Freud (2010) até os autores e estudiosos da área como os citados no trabalho o luto ilustra a perda de um objeto, uma figura amada que transforma e ocasiona em sua falta fatores de sofrimento e alienação, trazendo na grande ausência algum sentido de penosidade, mudez e dor. Nessa premissa, complementa Leader (2011, p. 104):

Somos encorajados com grande frequência a "superar" uma perda; no entanto, a pessoa enlutada e aqueles que têm experiência em perdas trágicas sabem muito que se trata menos da questão de superar a perda e dá sequência à vida do que encontrar uma forma de tornar essa perda parte da vida. Viver com a perda é o que importa (...).

Enfim, a prioridade de um luto é requisitada, mas nem sempre anunciada imediatamente. O tempo de sentir esse processo de enlutamento é de cada um e o passo dado para compreendê-lo também. Para tanto, viver, abraçar e garantir os passos do percurso da experiência dessa dor é apostar em um crescimento aflitivo, mas necessário e vital para ser um ser humano. 


\section{A felicidade, de quem?}

Mulher contorcida e trucidada de uma aflição inominável em posição fetal por cima de uma cama. Tal imagem imortaliza a capa do livro de Darian Leader, intitulado Além da depressão (LEADER, 2011). Essa informação seria irrelevante se não fosse por uma intenção: demonstrar que a infelicidade só é possível se um dia se entendeu o que era ser feliz, envergando-se a uma comparativa de sensações e emoções. Aproxima-se agora a gravura exemplificativa e, após a leitura da obra, percebe-se em diversos trechos que a depressão é um sintoma de alerta contra os estímulos nocivos da sociedade/pais/companheiros ou do contraste entre o avatar que ela exige que o homem assuma e o real personagem de si próprio travado na sua expressão de liberdade.

Quando se pensa na perspectiva contrária à alteridade, questiona-se acerca de um malestar no qual a padronização de caminhos é a saída para uma possível resolução, o de fazer parte de um mundo que aparenta não se perceber mundano, pois se cobre da persona da perfeição e da tirania da felicidade rasa, distante de uma noção de empatia compreensiva e, até mesmo no termo aqui não utilizado como bíblico, uma fraternidade escassa. Dessa maneira, Kehl (2009, p. 91) agrega entendimento ao dizer:

Que muitas vezes as simples manifestações de tristeza sejam entendidas (e medicadas) como depressões graves só faz confirmar essa ideia. A tristeza, os desânimos, as simples manifestações da dor de viver parecem intoleráveis em uma sociedade que aposta na euforia como valor agregado a todos os pequenos bens em oferta no mercado.

A renúncia aos prazeres individuais configura a característica de um modo de viver em coletividade, pois se entende que a vida social e relacional exige adaptações e negações de vontades para que se associe a um grupo com um ideal diferente, porém um excesso de abstenção de desejos impostos beira ao esgotamento do indivíduo em suas possibilidades autênticas de se mostrar no mundo. Isto incita pensar que situações como essas são boicotadas por uma vontade alheia de pluralidade e multifaces, pois o desejo do outro, o querer dos outros, transforma o sujeito nesse próprio outro dissimulado em originalidade.

Essa fronteira que percorre tanto o determinismo quanto o livre arbítrio choca e faz brotar diversas reflexões a ponto de perceber que a transitoriedade entre esses dois planos é a saída equilibrada para se pensar uma harmonia de vida, não focando no papel da felicidade como essa necessidade imediata, de acordo com o possível e habitável por cada um, valorizando sempre a dialógica e a fonte de reciprocidade e cordialidade entre pares, entre grupos, tendo 
como premissa maior o contato mais próximo consigo mesmo, condição vital para habitar suas experiências harmoniosamente (LEADER, 2011).

Salienta-se, de igual maneira, que a cultura dos tempos atuais manifesta eficazmente uma aversão ao momento de percalço e dissabores enfrentados, negando ou coagindo de forma displicente o experienciar do conflito e sua vivência performática no intuito de navegar nessas complicações em seu começo, meio e fim, cicatrizando e viabilizando o que era dor em aprendizado. Para concluir sobre o infortúnio de não se abastecer de felicidade em tempos truculentos, o resumo feito é de que cada passo feito pelo homem em sua história parece desamparar, ficar mais violento e instintivo quanto a sua relação com o outro em sua identidade primeira e, também, no que concerne ao respeito à sua personalidade, interpelando a situação de homem, detalhando nesse cenário de rigor a incapacidade de abarcar empaticamente o projeto de vida que não é o particular e sim, o do outro.

Nessa dinâmica Barros Filho e Karnal (2016, p. 59) acrescentam:

Se assim vivermos, é porque afetamos o mundo ininterruptamente e vice-versa. Portanto, toda perspectiva de estabilidade é desmentida pelo fluxo da vida. Toda esperança de permanência é desmentida pelo trânsito inexorável das relações com o mundo e dos fluxos vitais.

O ser humano inevitavelmente é um ser de transmutação diária, formando-se nas constantes relações e impactos naturais que desdobram em sua vida, significado e evolução de homem enriquecido de experiências.

\section{Conclusão}

No intento de se aprofundar na investigação do fenômeno depressivo, permeou-se pelas instâncias de outros eventos fenomênicos como a felicidade e o luto. Buscou-se, a priori, encaixá-los como sucedâneos e fatos de simetria correlacional chegando a possíveis inferências de que um funciona engrenado ao outro, pois tal acontecimento fez ou ainda faz parte desse hiato existencial e lesivo ao ser tratado aqui como melancolia ou depressão.

Destarte, discutiu-se sobre liberdade, fugas e anseios que partem da vontade do indivíduo em resgatar-se. Nesse intervalo, colocou-se a perspectiva indagativa de se é possível na probabilidade real conseguirmos escapar, indo de encontro e travando uma batalha com a correnteza determinista do século XXI. Acredita-se, defronte aos apontamentos, que a forma essencial para menear contrariamente a essa correnteza contemporânea e banalizadora seria a tomada de consciência diante dos fatos, a autorização de viver suas demandas pesarosas e 
garantir o aspecto saudável de vivenciar as perdas e acreditar na sua própria felicidade, não como um costume e função empregado por outrem, mas como um combustível peculiar a seu crescimento pessoal.

É considerável salientar que em momento algum põe-se à temática e o descerrar desse artigo como algo fechado ou uma ideia de pronta totalizada e inflexível, e sim, deseja-se aqui promover a discussão de forma a entender e absorver, na medida do possível, resoluções, contestações e em longo prazo uma fotografia não menos válida do que estamos passando e aparentemente deixando passar sem a cautela do esforço analítico.

Isto posto, os autores que contribuíram para a pesquisa trataram com solicitude a situação particular de nossa era demonstrando não fugir das tradições teóricas do modo de pensar o mundo, mas colocando com sabedoria seus posicionamentos, auxiliando no trato de percurso do artigo. Concluindo, ao ver-se a indicativa dos aparatos técnicos, é necessário acrescer a busca imediata pelo resgate do viver, do sentir e de seus valores e fontes originárias, pensando como a empatia, a ação de refletir em nós de forma interna e exógena, tem sua potência terapêutica em tempos tão difíceis de acessar autenticamente o contexto do outro. Em meio a tudo isso, fica o arriscar na tentativa de entender as chances e os bloqueios do que é ser lançado ao mundo. Acentuando que galgar nos roteiros da vida é nunca pairar na mediocridade da mesmice, entregando-se ao desafio de viver as novidades e suas aparições no tempo que é vivo e engajado nas sucessivas unicidades da existência.

\section{Referências bibliográficas}

BARROS FILHO, C. de; KARNAL, L. Felicidade ou morte. São Paulo: Papirus 7 mares, 2016.

CAMUS, A. O mito de Sísifo. Rio de Janeiro: BestBolso, 2013.

DALGALARRONDO, P. Psicopatologia e semiologia dos transtornos mentais. Porto Alegre: Artmed, 2008.

D’ASSUMPÇÃO, A. E. Sobre o viver e o morrer. Petrópolis: Vozes, 2011.

FREUD, S. "Luto e melancolia". In: - Sigmund Freud Obras Completas. v. 12. Tradução de Paulo César de Souza. São Paulo: Companhia das Letras, 2010. (Trabalho original publicado em 1917).

GIANNETTI, E. Felicidade. São Paulo: Companhia das Letras, 2002.

GIL, A. C. Métodos e técnicas de pesquisa social. São Paulo: Atlas, 2008. 
HADOT, P. A filosofia como maneira de viver: entrevistas de Jeannie Carlier e Arnold I. Davidson. São Paulo: É realizações, 2016.

KEHL, M. R. O tempo e o cão. São Paulo: Boitempo, 2009.

KOVACS, M. J. Morte e Desenvolvimento Humano. 2ed. São Paulo: Casa do Psicólogo, 1992.

KÜBLER-ROSS, E. Sobre a morte e o morrer: O que os doentes terminais têm para ensinar a médicos, enfermeiras, religiosos e aos seus próprios parentes. São Paulo: Martins Fontes, 2008 .

LARROSA, J. La experiencia de la lectura: estudios sobre literatura y formación. México: FCE, 2003.

LEADER. D. Além da depressão: novas maneiras de entender o luto e a melancolia. Rio de Janeiro: BestSeller, 2011.

MARCONDES, D. Iniciação à história da filosofia: Dos pré-socráticos a Wittgenstein. Rio de Janeiro: Zahar, 2007.

PARKES, M. C. Luto: estudos sobre a perda na vida adulta. São Paulo: Summus, 1998.

ROSA, G. A. M e. SANTOS, dos B. R. "Repercussões das redes sociais na subjetividade de usuários: Uma revisão crítica da literatura". Temas em psicologia. Ribeirão Preto, v.23, n4, p. 923 - 927, dez. 2015.

SADOCK, B. J. SADOCK. V. A. Compêndio de psiquiatria: Ciência do comportamento e psiquiatria clínica. Porto Alegre: Artmed, 2007.

SILVA, G. C. R. F da. "O método científico na psicologia: Abordagem qualitativa e quantitativa”, 2010. Disponível em: < http://www.psicologia.pt/artigos/textos/A0539.pdf>

VIEIRA, C. Depressão-Doença: O grande mal do século XXI: teorias, conceitos, sintomas, sinais, métodos de tratamento. Petrópolis, RJ: Vozes, 2016.

VILHENA, M. PRADO, Y. Z. C. "Dor, angústia e automutilação em jovens - considerações psicanalíticas”. Adolescência \& saúde, v.12, n2, p. 94- 98, abr/jun. 2015.

Recebido em: Julho de 2017 Aprovado em: Dezembro de 2017 